Institute of Internet and Intelligent Technologies

Vilnius Gediminas Technical University

Saulètekio al. 11, 10223 Vilnius, Lithuania

http://www.isarc2008.vgtu.lt/
The $25^{\text {th }}$ International Symposium on Automation and Robotics in Construction

June 26-29, 2008

ISARC-2008

\title{
AUTOMATED EVALUATION OF ALTERNATIVE SOLUTIONS OF BUILDING DESIGN
}

\author{
Jonas Šparauskas \\ Dept of Construction Technology and Management \\ Vilnius Gediminas Technical University, Sauletekio al. 11, 10223 Vilnius, Lithuania \\ E-mail: Jonas.Saparauskas@st.vtu.lt
}

\begin{abstract}
The purpose of this article - is to create theoretical model in order to enable in automated manner to compare different solutions of building, its part or structure design and to select the best alternative under specific circumstances. Summarizing variant design theory and practice applications in Lithuania and abroad, evaluation model of alternative design solutions is created. By assistance of this model it will be possible to evaluate design solutions which can be characterized by quantitative and qualitative indicators which possibly have different weight, dimention and direction of optimization (maksimization or minimization). Automated alternatives' evaluation working principle is demonstrated by selecting the best facade system to cover the building. For this purpose four building facades alternatives is under consideration. It is soundly described how all stages of alternatives comparison is performed and which multiple criteria evaluation methods can be applied by selecting the best alternative.
\end{abstract}

\section{KEYWORDS}

Automated evaluation, theoretical model, facade system, multiple criteria evaluation methods

\section{INTRUDUCTION}

Usually the lifecycle of every building covers the following stages: generation of idea (predesign proposals), design, construction, maintenance, reconstruction (if possible) and demolition (disposal). Some authors (O'Sullivan etc) [1] distinguished life-cycle elements otherwise (see Fig 1) but nevertheless one of the most important stages remaines the building design preparation. On building design depends forthcoming: construction technology, terms and price of construction, aesthetical view and performance of building (usage term, lifecycle costs, quality of life level), environmental impact during building demolition, and also other features.

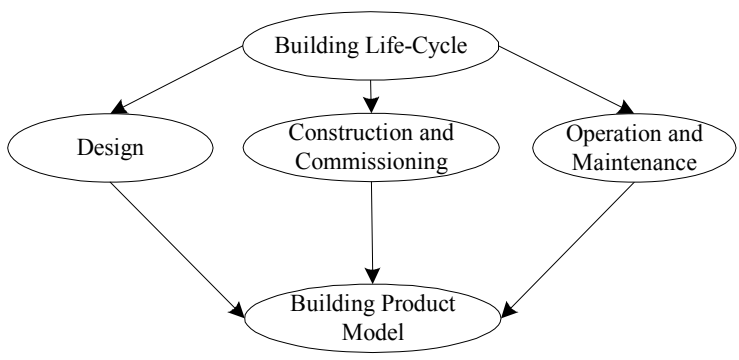

Figure 1. Building life-cycle 
How to take the right design solution? In many cases it is not possible to do that from the first time. Therefore, one have to look through many alternatives. Just after analysis of all advantages and disadvantages of different design solutions and their magnitude it is possible to say which solution of building (or its part) design is the best. Procedure mentioned seems very simple in this regard, however many labour expenditures are needed.

The goals to be achieved in this contribution are as following:

- to carry out a survey on building design processes;

- $\quad$ to survey previous attempts assessing building design alternatives;

- to suggest and describe assessment methodology to compare building design alternatives;

- to gain qualitative and quantitative information on some building design options;

- to perform calculations comparing different building design alternatives of particular building structure;

- to present conclusions about suitability of suggested methodology.

\section{IMPORTANCE OF BUILDING DESIGN PROCESS}

Globally, scientists-engineers are trying to solve many different problems in building design stage.

Wen [2] analysed structural failures in recent earthquakes and hurricanes. The author has exposed the weakness of current design procedures and shown the need for new concepts and methodologies for building performance evaluation and design. A reliability-based framework for design is proposed for this purpose. Performance check of the structures is emphasized at two levels corresponding to incipient damage and incipient collapse. Minimum lifecycle cost criteria are proposed to arrive at optimal target reliability for performance-based design under multiple natural hazards.
Building evacuation simulation provides designers with an efficient way of testing the safety of a building before in design stage. Pelechano and Malkawi [3] present a review of crowd simulation models and selected commercial software tools for high rise building evacuation simulation. The commercial tools selected (STEPS and EXODUS) are grid-based simulations, which allow for efficient implementation but introduce artifacts in the final results. The authors focuses on describing the main challenges and limitation of these tools, in addition to explaining the importance of incorporating human psychological and physiological factors into the models.

Al-ajmi and Hanby [4] explored reduction of energy consumption in buildings in desert climate Kuwait. Authors used building and plant simulation programs as a design tool for carrying out the performance of proposed building designs and to evaluate the effects of varying design parameters. A building model representative of a typical Kuwaiti dwelling has been implemented and encoded within the TRNSYS-IISIBAT environment. A typical meteorological year for Kuwait was prepared and used to predict the cooling loads of the airconditioned dwelling. Several parametric studies were conducted to enable sensitivity analyses of energy-efficient domestic buildings to be carried out, namely relating to building envelope, window type, size and direction, infiltration and ventilation.

Vakili-Ardebili and Boussabaine [5] analysed a complex process - Sustainable building design dynamism. Authors emphasize that consideration of different aspects such as environment, economy and society in addition to design characteristics makes the process of design even more complex. Also the subjectivity in design decisions makes the process of ecological assessment quite vague and difficult. Fuzzy logic techniques could help to compensate for the lack of full knowledge and subjectivity of design parameters. Hence, a fuzzy methodology is proposed in this paper for modelling and representing ecobuilding design indicators. The model is based on three linguistic variables. The developed model is able to indicate the low eco-efficient and high ecoefficient bands of a particular building design based on a set of eco-design indicators. 
McDermott etc [6] in their research examined the interaction between user activity and dwelling design and how this might affect health and safety. It aimed to identify how people use features within new homes and how this may limit the protection afforded by building design, codes and regulations. Forty, home-based, semi-structured, in-depth interviews and home inspections were conducted with individuals recently inhabiting a new home. A range of behaviours were reported in relation to building features including fire doors, pipes and cables, and loft access, which may lead to increased risk of injury or ill-health. For example, occupiers described interfering with the self-closing mechanisms on fire doors and drilling into walls without considering the location of services. They also reported knowingly engaging in unsafe behaviour when accessing the loft, increasing their risk of falls. The accounts suggest that designers and builders need to give greater consideration to how occupier behaviour interacts with building features so that improvements in both design and occupier education can lead to improved health and safety.

Da Graça, etc [7] tried to present a method for evaluating and optimising environmental comfort parameters of school buildings during the preliminary stages of design. In order to test the method, 39 existing public school building designs in the State of São Paulo, Brazil, had their plans analysed and characterised in relation to their influence on environmental comfort. Four aspects of comfort were considered: thermal, acoustic, natural lighting and functionality. Maximisation of various aspects of comfort simultaneously was shown to be impossible, but compromise solutions could be found.

A case-study of a public building is presented as an example of the adequacy of timely analyses of building performance, based on a preliminary architectural design [8]. The options were created and analysed with the help of the VisualDOETM building simulation tool, aiming at a comfortable and energy efficient building. Several parameters were used for enabling the sensitivity analyses, namely relating to wall structure and materials, window frames, HVAC system, etc.
Luck and McDonnell [9] performed an investigation of the exchange of ideas and information between an architect and building users in the early stages of the building design process before the design brief or any drawings have been produced. The purpose of the research is to gain insight into the type of information users exchange with architects in early design conversations and to better understand the influence the format of design interactions and interactional behaviours have on the exchange of information. Recommendations are made on the format and structure of pre-briefing conversations and on designers' strategies for raising the level of information provided by the user beyond the functional or structural attributes of space.

Rounce [10] emphasised the need to reduce waste and improve efficiency of the design process. Author states that quality management and its application to the building design process is still a relatively new technique as are the concepts of waste, quality and efficiency. Factors contributing to waste in building design are examined and appear to be mainly management problems. The paper concludes with management recommendations to reduce wastage and improve quality and profitability in architectural design.

\section{THE MODEL FOR ASSESSMENT OF BUILDING DESIGN ALTERNATIVES}

In the scientific researches one can find various methodologies, models or algorithms to evaluate alternatives.

Wang etc [11] proposed a method to assess costeffectiveness of insulated exterior walls of residential buildings in cold climate. By considering energy savings, increased usable floor area, construction costs, insulation replacement and salvage values, the method calculated the main cost or benefit difference of using insulated exterior walls throughout a building lifecycle compared with the typical non-insulated solid clay brick walls, and subsequently defined a cost-effectiveness indicator (CEI) for measuring the overall cost efficiency of insulated exterior walls. 


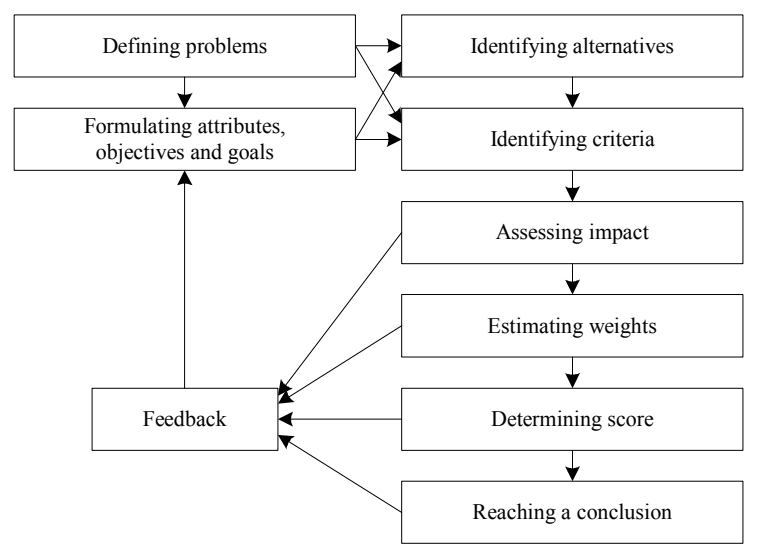

Figure 2. Sustainability model for project appraisal

The main objectives of Ding [11] were to examine the development, role and limitations of current environmental building assessment methods in ascertaining building sustainability used in different countries which leads to discuss the concept of developing a. sustainability model for project appraisal based on a multi-dimensional approach (see Fig 2), that will allow alternatives to be ranked.

Author developed his own model for assessment of design alternatives (see Fig 3). If weigts of indicators are not equal, then values of weights according the following methodology has to be find (see Fig 4).

\section{SELECTION OF THE MOST APPLICABLE DECISION-MAKING METHODS}

Determining the most applicable multiple criteria decision-making method three main criterias were used: 1) consistency of calculation results, 2) labour expenditures, necessary for the task solution manually, and 3) ease of understanding. During the survey six different methods were compared: simple additive weighting (SAW), multi-criteria decision making method MCDM-23, analytic hierarchy process (AHP), ELECTRE III, TOPSIS and multiple criteria complex proportional evaluation method (COPRAS) [13]. For the comparison of the methods simplified task of sustainable urban development evaluation was structured. This task is identical with evaluation of building designs. The survey's results are presented in Table 1. From the Table 1 one can

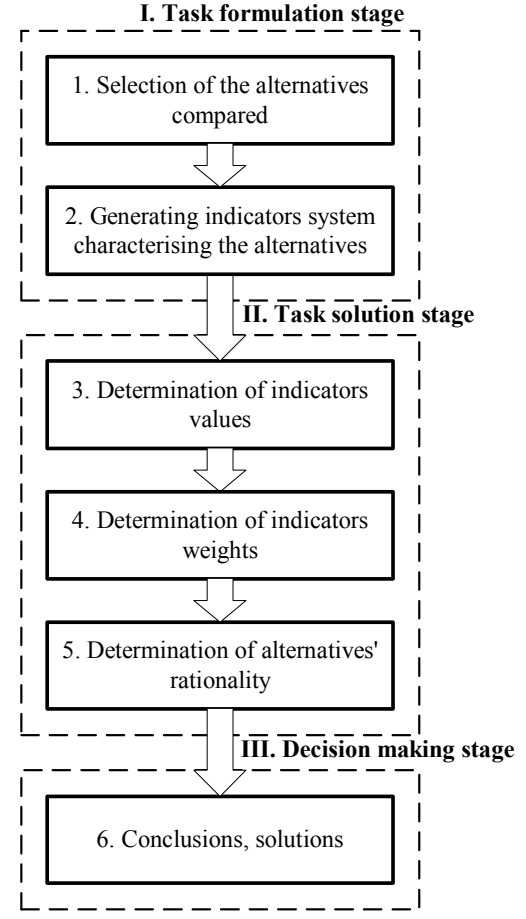

Figure 3. Evaluation model of alternative comparison

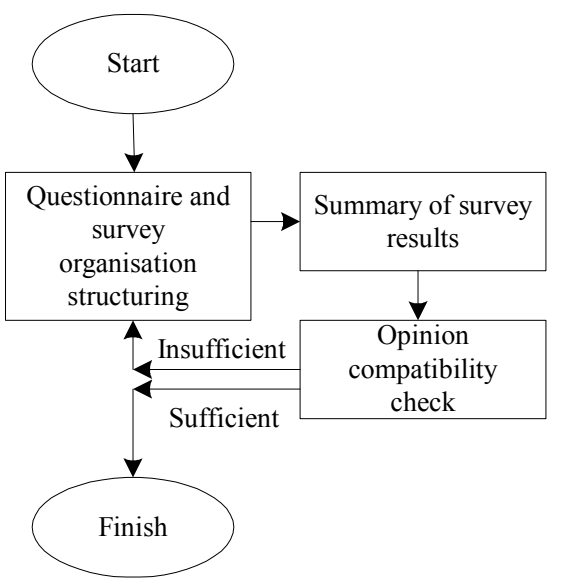

Figure 4. Determination weights of indicators

see that for sustainability assessment tasks the most applicable are two decision-making methods, SAW and MCDM-23. Both methods present constant calculation results, they have little labour expenditures and they are easy to understand. SAW and MCDM-23 are taking into account both values 
Table 1. Comparison of multiple criteria decision making methods

\begin{tabular}{|c|c|c|c|c|}
\hline \multirow[b]{2}{*}{ Method } & \multicolumn{4}{|c|}{ Evaluation criteria } \\
\hline & $\begin{array}{l}\text { Consistency of } \\
\text { results }\end{array}$ & $\begin{array}{l}\text { Labour expenditures, } \\
\text { necessary for the task solution } \\
\text { manually* }\end{array}$ & $\begin{array}{c}\text { Ease of } \\
\text { understanding }\end{array}$ & Other features \\
\hline SAW & Constant & Little & Easy & \\
\hline MCDM-23 & Constant & Little & Easy & Forms an ideal alternative \\
\hline AHP & Variable & Little & Easy & \\
\hline ELECTRE III & Variable & Large & Complicated & $\begin{array}{c}\text { Takes into account } \\
\text { variations of indices } \\
\text { values }\end{array}$ \\
\hline TOPSIS & Variable & Little & Easy & \\
\hline МССРЕМ & Variable & Little & Easy & \\
\hline
\end{tabular}

*This criteria is not important when multi-attribute evaluation is being performed entirely by computer.

and weights of indicators. When weights of indicators by assessing building designs are the same, then their sum is equal of one $\sum_{i=1}^{n} w_{i}=1$. SAW and MCDM-23 methods do not have any specific requirements, simply uses qualitative and quantitative information expressed by scores or other units.

\section{CASE STUDY: EVALUATION OF ALTERNATIVE BUILDING DESIGNES}

\subsection{Establishment of indicator system}

Automated alternatives' evaluation working principle is demonstrated by selecting the best facade system to cover the building. For this purpose four building facades alternatives is under consideration (see Table 2): cellular concrete masonry, covered by roockwool plates and decorative plaster surface; "sandwich" facade panels; gas silicate masonry, covered by roockwool and "Minerit" facade plates; aluminium glazing facade [14].

\subsection{Calculation according to multi-criteria decision-making method MCDM-23}

This method developed by National Renewable Energy Laboratory, USA (Solar Heating and Cooling Programme, Task 23) [15]. To transform different quantitative units of indicators into scores so-called "4-to-10" measurement scales are being used (1-3 formulas). Then, the simple additive weighting is used to aggregate the scores into one score. The method proposed consists of steps, as follows.

Step 1. Development of measurement scales for the indicator.

1-st indicator: $900=4,300=10$ scores;

2-nd indicator: $20=4,5=10$ scores;

3-rd indicator: $1=4,4=10$ scores;

4-th indicator: $1=4,5=10$ scores;

5-th indicator: $5=4,50=10$ scores;

6-th indicator: $1=4,3=10$ scores.

7-th indicator: $1=4,3=10$ scores;

8-th indicator: $1=4,10=10$ scores;

9-th indicator: $100=4,10=10$ scores;

10-th indicator: $425=4,50=10$ scores;

11-th indicator: $1=4,3=10$ scores;

12-th indicator: $1=4,5=10$ scores.

Step 2. Qualitative or quantitavive values of indicators are transformed into scores. Formula (1) is used when indicators are maximised and formula (2) is used when indicators are minimised.

$$
\begin{aligned}
& x_{i j}=4+\frac{a_{i j}-a_{j}^{\min }}{\operatorname{tg} \alpha} . \\
& x_{i j}=4+\frac{a_{j}^{\max }-a_{i j}}{\operatorname{tg} \alpha} .
\end{aligned}
$$


Table 2. Indicator system for façade's systems comparison

\begin{tabular}{|c|c|c|c|c|c|c|}
\hline \multirow{2}{*}{ Indicators (Criterias) } & \multirow{2}{*}{ Units } & \multirow{2}{*}{$\begin{array}{l}\text { Min./ } \\
\text { Max. }\end{array}$} & \multicolumn{4}{|c|}{ Facades' alternatives } \\
\hline & & & 1 & 2 & 3 & 4 \\
\hline I. Economy & & & & & & \\
\hline 1) Instalation cost & $\mathrm{Lt} / \mathrm{m} 2$ & - & 370 & 314 & 480 & 850 \\
\hline 2) Labour intensivity by assembling & Days & - & 11.0 & 7.00 & 10.0 & 16.0 \\
\hline II. Performance parameters & & & & & & \\
\hline 3) User friendliness & Points & + & 2.69 & 3.37 & 3.09 & 3.17 \\
\hline 4) Durability & Points & + & 2.75 & 3.27 & 3.67 & 4.10 \\
\hline 5) Warranty & Points & + & 5.00 & 35.0 & 30.0 & 50.0 \\
\hline III. Environmental impact & & & & & & \\
\hline 6) Environmental friendliness & Points & + & 1.63 & 1.72 & 1.87 & 1.91 \\
\hline 7) Recovery (utilization) & Points & + & 1.47 & 2.07 & 1.38 & 2.22 \\
\hline 8) Aesthetics & Points & + & 7.11 & 5.60 & 7.82 & 8.25 \\
\hline IV. Structural properties & & & & & & \\
\hline 9) Weight of structure & $\mathrm{Kg} / \mathrm{m}^{2}$ & - & 88.0 & 12.6 & 94.0 & 23.0 \\
\hline 10) Thickness of structure & $\mathrm{mm}$ & - & 410 & 100 & 410 & 65.0 \\
\hline V. Physical properties & & & & & & \\
\hline 11) Sound isolation & Points & + & 2.93 & 2.13 & 2.87 & 1.10 \\
\hline 12) Fire resistance & Points & + & 1.98 & 3.21 & 2.94 & 4.37 \\
\hline
\end{tabular}

there: $x_{i j}-$ value of $n$-th indicator in scores; $a_{i j}-$ value of $n$-th indicator in units; $a_{j}^{\max }$ - maximum value of $n$-th indicator in scale (scores); $a_{j}^{\min }-$ minimal value of $n$-th indicator in scale (scores);

$\operatorname{tg} \alpha=\frac{a_{j}^{\max }-a_{j}^{\min }}{6}$.

Step 3. Aggregate scores (formula 4), analyse results and make decisions.

$$
S_{M C D M-23}=\max _{j} \sum_{i=1}^{m} x_{i j} \times w_{i}, j=1, \ldots, n .
$$

The computer program MCDM-23 was downloaded from Internet (http://ktlabo.cm.kyushuu.ac.jp/e/MCDM E.htm) and calculations were performed. Results is presented in Figure 5.

\subsection{Calculation according to Simple additive weighting (SAW)}

Simple Additive Weighting method (SAW) is probably the best known and very widely used. The model is used to aggregate the scores into one score based on the criteria weights [15-19].

At first, the scores are normalised (converted) by formulas:

$$
\begin{aligned}
& x_{i j}=\frac{a_{i j}}{a_{j}^{\max }} ; \\
& x_{i j}=\frac{a_{j}^{\min }}{a_{i j}} .
\end{aligned}
$$




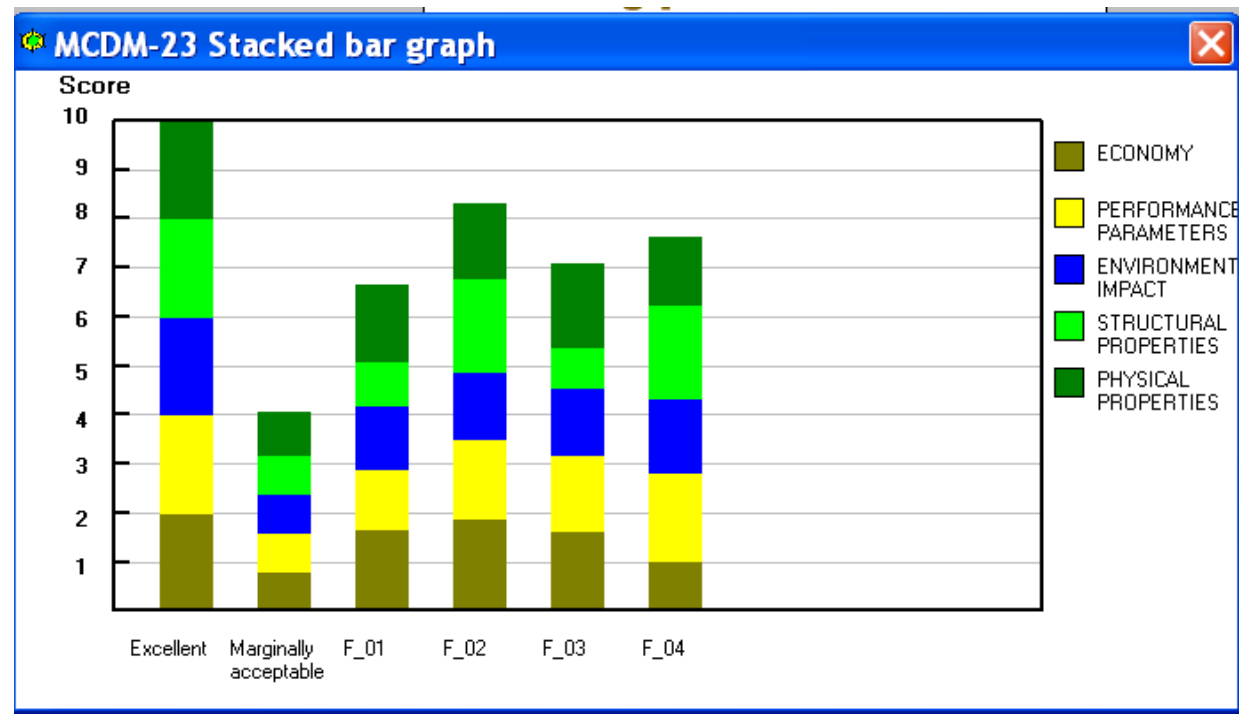

Figure 5. Outprints from the computer program MCDM-23

where $a_{i j}$ is the score for the criterion. When criterions are maximised then formula 5 has to be used and formula 6 has to be used when criterions are minimised.

Then the scores are aggregated into one score:

$S_{S A W}=\max _{j} \sum_{i=1}^{m} x_{i j} \times w_{i}, j=1, \ldots, n$.

where $S_{S A W}$ is the total score, $\mathrm{n}$ is the number of criteria, $w_{i}$ is the weight of the criterion, and $x_{i j}$ is the normalised score for the criterion.

After calculations according to formulas (5-7) the following results have been obtained: $S_{\mathrm{F}-1}=5.99$; $S_{\mathrm{F}-2}=8.43 ; S_{\mathrm{F}-3}=6.88 ; S_{\mathrm{F}-4}=8.06$.

\section{CONCLUSIONS}

The research revealed that building design stage is extremely important by solving technical, economical, social and environmental problems of building project developers, inhabitants and other interest parties.

The novel evaluation model for comparison of alternative design solutions is suggested.
For automation of calculations most applicable multiple criteria methods are selected: Multi-criteria decision-making method MCDM-23 and Simple additive weighting (SAW).

Methods mentioned are applied by evaluating different building facades. Both methods show that designers should prefer "sandwich" facade panels to cover building (see "Index of priority" in Fig 6).

\section{REFERENCES}

[1] O'Sullivan, D. T. J.; Keane, M. M.; Kelliher, D. and Hitchcock, R. J. (2004) Improving building operation by tracking performance metrics throughout the building lifecycle (BLC). Energy and Buildings, Vol. 36, Issue 11, p. 1075-1090.

[2] Wen, Y. K. (2001) Reliability and performancebased design. Structural Safety, Vol. 23, Issue 4, p. 407-428.

[3] Pelechano, N. and Malkawi, A. (2008) Evacuation simulation models: Challenges in modeling high rise building evacuation with cellular automata approaches. Automation in Construction, Vol. 17, Issue 4, p. 377-385.

[4] Al-ajmi, F. F. and Hanby, V. I. (2008) Simulation of energy consumption for Kuwaiti domestic buildings. Energy and Buildings, Vol. 40, Issue 6, p. 11011109. 


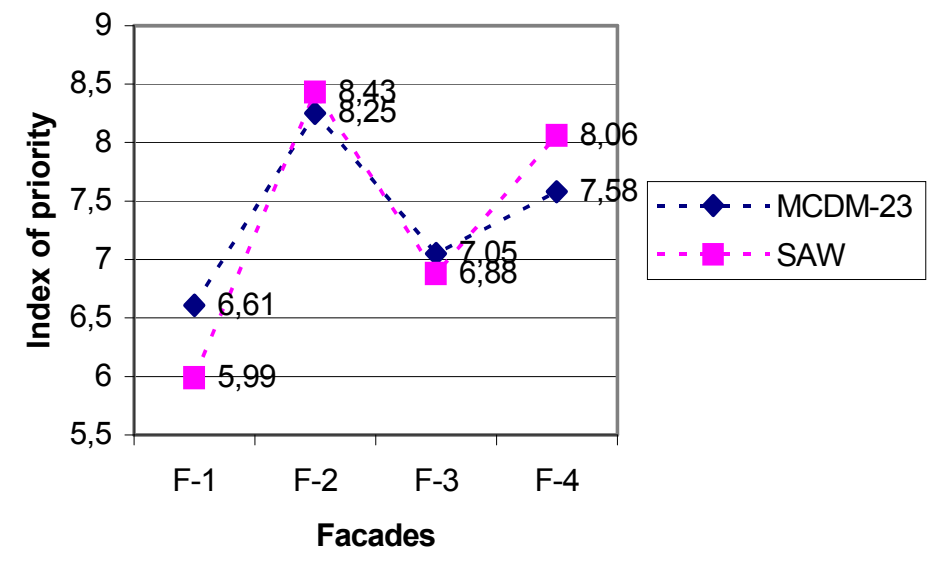

Figure 6. Facades' alternatives comparison results calculated by MCDM-23 and SAW methods

[5] Vakili-Ardebili, A. and Boussabaine, A. H. (2007) Application of fuzzy techniques to develop an assessment framework for building design ecodrivers. Building and Environment, Vol. 42, Issue 11, p. 3785-3800.

[6] McDermott, H.; Haslam, R. and Gibb, A. (2007) The interaction between design and occupier behaviour in the safety of new homes. Accident Analysis \& Prevention, Vol. 39, Issue 2, p. 258-266.

[7] da Graça, V. A. C.; Kowaltowski, D. C. C. K.; and Petreche, J. R. D. (2007) An evaluation method for school building design at the preliminary phase with optimisation of aspects of environmental comfort for the school system of the State São Paulo in Brazil. Building and Environment, Vol. 42, Issue 2, p. 984999.

[8] de Almeida Ferreira Tavares, P. F. and de Oliveira Gomes Martins, A. M. (2007) Energy efficient building design using sensitivity analysis-A case study. Energy and Buildings, Vol. 39, Issue 1, p. 2331.

[9] Luck, R. and McDonnell, J. (2006) Architect and user interaction: the spoken representation of form and functional meaning in early design conversations. Design Studies, Vol. 27, Issue 2, p. 141-166.

[10] Rounce, G. (1998) Quality, waste and cost considerations in architectural building design management. International Journal of Project Management, Vol. 16, Issue 2, p. 123-127.

[11] Wang, Y.; Huang, Z. and Heng, L. (2007) Costeffectiveness assessment of insulated exterior walls of residential buildings in cold climate. International Journal of Project Management, Vol. 25, Issue 2, p. 143-149.

[12] Ding, G. K.C. (2008) Sustainable construction - The role of environmental assessment tools. Journal of Environmental Management, Vol. 86, Issue 3, p. 451-464.

[13] Šaparauskas, J. (2004) Multi-attribute evaluation and modelling of sustainable urban development. Doctoral Dissertation, $143 \mathrm{p}$.

[14] Povilavičius, M. (2007) Application of new design solutions in construcion. Masters final work. Vilnius, $62 \mathrm{p}$.

[15] Balcomb, J. D.; Curtner, A. (2000) MCDM-23: a multi-criteria decision making tool for buildings. In: Proceedings of International Conference on Sustainable Building. Maastricht, The Netherlands, October 22-25, p. 219-221.

[16] Hwang, C. L.; Yoon, K. (1981) Multiple (Attribute) Decision Making. Methods and Applications. Berlin, Heidelberg, New York, $259 \mathrm{p}$

[17] Peldschus, F.; Zavadskas, E. K.; Ustinovičius, L.; Turskis, Z. (2004) Game theory in building technology and management (Lošimų teorija statybos technologijoje ir vadyboje). Vilnius: Technika, $196 \mathrm{p}$. (in Lithuanian).

[18] Zavadskas, E. K.; Kaklauskas, A. (1996) Systemotechnical evaluation of buildings. Vilnius: Technika, 280 p. (in Lithuanian).

[19] Triantaphyllou, E. (2000) Multi-Criteria Decision Making Methods: A Comparative Study. Kluwer Academic Publishers, Dordrechet, 290 p. 